\title{
The Effect of HIV Self-Testing Delivery Models on Female Sex Workers' Sexual Behaviors: A Randomized Controlled Trial in Urban Uganda
}

\author{
Katrina F. Ortblad ${ }^{1}$ (D) Daniel Kibuuka Musoke ${ }^{2}$. Thomson Ngabirano ${ }^{3} \cdot$ Aidah Nakitende $^{2} \cdot$ Guy Harling ${ }^{1,4}$. \\ Jessica E. Haberer ${ }^{5}$. Margaret McConnell ${ }^{6}$. Joshua A. Salomon ${ }^{1,7}$. Catherine E. Oldenburg ${ }^{8,9,10}$. \\ Till Bärnighausen ${ }^{1,11,12}$
}

Published online: 16 January 2019

(c) The Author(s) 2019

\begin{abstract}
HIV self-testing increases recent and frequent HIV testing among female sex workers (FSWs) in urban Uganda. Using results from a randomized controlled trial, we aim to establish the effect of HIV self-testing delivery models on FSWs' sexual behaviors in this setting. Clusters of one peer educator and eight participants were 1:1:1 randomized to: (1) direct provision of an HIV self-test, (2) provision of a coupon for facility collection of an HIV self-test, or (3) referral to standardof-care HIV testing services. Sexual behaviors were self-reported at 1 and 4 months. From October to November 2016, 960 participants were enrolled and randomized. At 4 months, there were no statistically significant differences in participants' sexual behaviors, including inconsistent condom use, across study arms. We do not find any changes in sexual risk-taking among FSWs in response to the delivery of HIV self-tests. Routine policies for HIV self-testing are likely a behaviorally safe component of comprehensive HIV prevention strategies.
\end{abstract}

Keywords HIV self-testing $\cdot$ Sexual behaviors $\cdot$ Condom use $\cdot$ Female sex workers $\cdot$ Uganda

\section{Introduction}

HIV self-testing has been proven to increase HIV testing in diverse populations and settings [1-10]. HIV self-testing may be particularly beneficial for female sex workers (FSWs), who- according to the World Health Organization (WHO) should test for HIV every 3 months, because they are at high risk of HIV acquisition [11]. Among FSWs in urban Uganda, the delivery of HIV self-tests increased recent and frequent

Katrina F. Ortblad

katort@uw.edu

1 Department of Global Health, University of Washington, 908 Jefferson St, 12th Floor, Seattle, WA 98104, USA

2 International Research Consortium, Kampala, Uganda

3 Uganda Health Marketing Group, Kampala, Uganda

4 Institute for Global Health, University College London, London, UK

5 Department of General Internal Medicine, Massachusetts General Hospital Global Health, Boston, MA, USA

6 Department of Global Health and Population, Harvard T.H. Chan School of Public Health, Boston, MA, USA
HIV testing [7], suggesting that self-testing can overcome some of the barriers to HIV testing that FSWs face, such as facility hours [12], stigma and discrimination by healthcare providers [12-15], and transportation costs [16]. How HIV self-tests were delivered to Ugandan FSWs additionally affected how often they tested: FSWs tested for HIV more frequently when self-tests were delivered to them directly by peer educators ('direct provision') versus when they had to collect self-tests from a healthcare facility ('facility collection') [7].

7 Department of Medicine, Stanford University, Stanford, CA, USA

8 Francis I. Proctor Foundation, University of California San Francisco, San Francisco, CA, USA

9 Department of Ophthalmology, University of California, San Francisco, San Francisco, CA, USA

10 Department of Epidemiology \& Biostatistics, University of California, San Francisco, CA, USA

11 Heidelberg Institute of Public Health, University of Heidelberg, Heidelberg, Germany

12 Africa Health Research Institute, Somkhele, KwaZulu-Natal, South Africa 
Other behaviors, besides HIV testing, that influence FSWs' risk of HIV transmission might also be affected by HIV selftests [17-19]—and affected differentially depending on how HIV self-tests are delivered. When FSWs receive an HIV selftest directly from a peer educator instead of from a healthcare facility, they miss the opportunity to interact with a healthcare provider and receive services (e.g., counseling) or items (e.g., condoms) available at healthcare facilities. When FSWs pickup HIV self-tests a healthcare facility, they might collect condoms and other free items, but still forgo counseling services. Reduced uptake of counseling services and reduced access to free condoms might increase sexual behaviors associated with HIV risk among FSWs. Conversely, it is also plausible that HIV self-testing approaches decrease FSWs' HIV riskrelated sexual behaviors. For instance, HIV self-testing may increase FSWs' feeling of control and self-efficacy regarding HIV prevention, which may lead to greater sexual negotiation power and reduced risk behaviors [20, 21].

While there have been few studies to date on the effect of HIV self-testing on sexual behaviors, those that exist suggest that HIV self-testing may reduce sexual behaviors associated with HIV risk [17-19]. Among men who have sex with men in high income settings, the availability of HIV self-tests made men more selective with whom they had sex [17, 18]. Among FSWs in Zambian transit towns, HIV self-testing significantly reduced FSWs' number of client and non-client sexual partners compared to standard testing services, and this effect was greater among FSWs who received HIV selftests directly from a peer educator compare to those who went to a healthcare facility to collect HIV self-tests [19].

Using data from a three-arm HIV self-testing randomized controlled trial among FSWs in urban Uganda [7], we measure the effect of direct provision of and facility collection of HIV self-tests on FSWs' sexual behaviors with client and non-client partners. Additionally we outline pathways through which the two different HIV self-test delivery models might affect FSWs' sexual behaviors (e.g., empowerment, hope, communication of HIV status, confidence in HIV status) and measure the effect of the interventions on these pathways. Understanding the effect of different HIV self-testing health systems delivery models on FSWs' sexual behaviors is important because many sub-Saharan African governments with generalized HIV epidemics consider FSWs a priority population for HIV prevention interventions [22] and are in the midst of rolling out HIV self-testing [23].

\section{Methods}

\section{Ethics Statement}

This study received Ethical Approval from the Institutional Review Board at the Harvard T.H. Chan School of Public
Health and the Mildmay Uganda Research and Ethics Committee. All participants provided written informed consent.

\section{Participants and Study Setting}

Between October to November 2016, FSWs in Kampala, Uganda were enrolled in a three-arm HIV self-testing cluster randomized controlled trial designed to measure the effect of different HIV self-testing delivery models on recent and frequent HIV testing (clinicaltrials.gov: NCT02846402). Complete methods for this study have been previously reported [7]. Participants were recruited by peer educators. Peer educators were referred by leaders from Kampala-based FSW peer organizations and clinics affiliated with Uganda's Most at Risk Population Initiative. All peer educators completed a 2-day training prior to participant enrollment. Eligible participants were: 18 years or older, reported the exchange of sex for money or goods in the past month, did not know their HIV status or reported being HIV-negative and not having recently tested for HIV (past 3 months), and were Kampala-based. Research assistants called potential participants for an initial eligibility screening. They then invited potential participants for a more detailed in-person eligibility assessment, which was followed by an invitation to participate in this trial.

\section{Study Design}

Peer educator-participant groups (one peer educator, eight participants) were randomized to: (1) direct provision of HIV self-tests, (2) provision of a coupon for healthcare facility collection of HIV self-tests, and (3) referral to standard-of-care HIV testing services. The randomization list was developed by the author CEO in R Studio (Version 3.3.1, The R Foundation for Statistical Computing, Vienna, Austria) in random blocks of 3, 6, and 9. Peer educator-participant group study assignments were placed in opaque, sealed envelopes that were opened by peer educator and research assistant, neither of whom knew the group assignment beforehand [7].

\section{Interventions}

Over the duration of the study, participants completed four peer educator visits: $0,0.5,1.5$, and 3 months after randomization. At these visits all participants received condoms, information on HIV prevention, and were encouraged to test for HIV at any standard testing facility. Participants in the HIV self-testing intervention arms additionally received one HIV self-test (OraQuick Rapid HIV-1/2 Antibody Test, OraSure Technologies, Bethlehem, PA) or one coupon, exchangeable for an HIV self-test at 10 participating private health facilities throughout Kampala, at the first and 
fourth peer educator visit [7]. HIV self-tests were distributed to participants in the intervention arms 3 months apart because this is the WHO's recommended frequency of HIV testing for FSWs [24]. The interim peer educator visits were designed to keep peers and participants engaged in the study and prevent loss to follow-up.

\section{Assessments}

Participants completed three quantitative assessments: a baseline assessment and two follow-up assessments. The baseline assessment occurred at participant enrollment, before randomization and distribution of HIV self-tests to participants in the intervention arms. The follow-up assessments occurred 1 and 4 months after the first peer educator visit. Socio-demographic characteristics were collected at baseline. Information related to recent HIV testing, including self-reported test results, and sexual behaviors with client and non-client partners was collected at all assessments. Research assistants collected the electronic data (CommCare, Dimagi, Inc., Cambridge, MA) in face-to-care interviews at private locations selected by participants (e.g. empty bar, home, etc.). Participants received 16,500 Uganda Shillings ( $\sim 5$ USD) upon completion of each assessment as compensation for their time.

\section{Sexual Behavior Outcomes}

We measured four sexual behaviors outcomes: the average number of clients per night, inconsistent condom use with clients, the number of non-clients sexual partners in the past month, and inconsistent condom use with non-client sexual partners in the past month. Participants were asked to selfreport the number of sexual clients they have on an average working night and the number of these with which they use condoms. Inconsistent condom use with clients was defined as not using a condom with at least one of these clients. Participants were additionally asked the number of sexual partners they had who were not clients in the past month and the number of these with whom they ever used condoms. Inconsistent condom use with non-clients was defined as never using a condom with at least one of these non-client sexual partners in the past month. Repeat clients and non-client sexual partners and condom use with these sexual partners are incorporated in these measures. If participants had a regular client with whom they do not use condoms, their condom use with clients was categorized as inconsistent. Similarly, if participants had a husband or boyfriend with whom they never use condoms, their condom use with non-clients was also be categorized as inconsistent. All sexual behavior outcomes were pre-specified for secondary analysis [25].

\section{Pathways for Sexual Behaviors}

We additionally measured the effect of the different HIV self-testing delivery models on upstream pathways that we hypothesized might affect FSWs' sexual behaviors. Figure 1 outlines the pathways we measured: empowerment, hope, communication of HIV status, and confidence in HIV status.

Empowered FSWs or those who are hopeful for their future might be more likely to negotiate condom use or be more selective about with whom they have sex [20, 26, 27]. Communication of HIV status between FSWs and their sexual partners might similarly effect FSWs' condom use or their decision to engage in any sexual activity [28, 29]. Knowledge of HIV status, acquired through HIV (self-)testing, might further affect HIV risk-related sexual behaviors depending on FSWs' concerns of HIV acquisition or transmission [30-34].

The potential pathways to sexual behavior change may differ between the two HIV self-testing delivery models, which provided differential motivation to visit healthcare
Fig. 1 Pathways upstream from FSWs' HIV risk-related sexual behaviors that may be affected by the different HIV self-testing delivery models. Pathway variables are depicted in dark gray boxes, while the mechanisms that might influence these pathways are depicted in light gray boxes

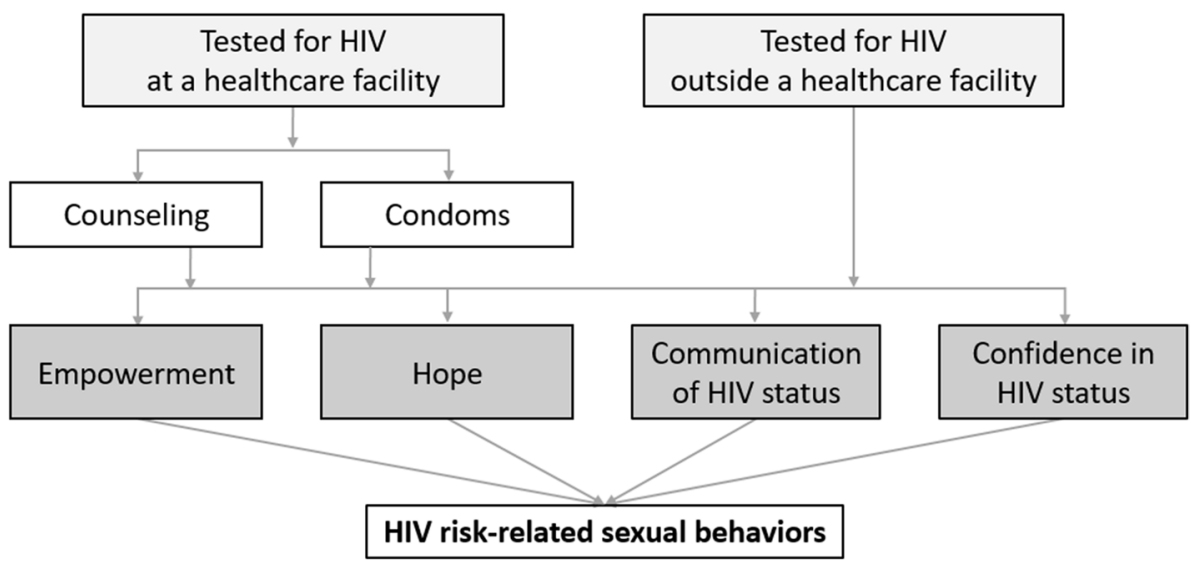

Mechanisms Pathways 
facilities-i.e., participants in the direct provision arm did not have to visit a healthcare facility at all to test for HIV, while participants in the facility collection arm needed to visit a healthcare facility but did not need to engage with a healthcare provider to test for HIV. We selected variables from the 4-month assessment that captured the potential pathways from an HIV-self-testing offer to sexual behaviors.

To measure empowerment, we calculated the proportion of participants who reported always using a condom when they wanted during sexual intercourse with clients in the past month [21] and the proportion of participants who reported always or often asking clients to share their HIV status before engaging in sex (five-point Likert scale). To measure hope, we calculated the proportion of participants that are not likely depressed on the PHQ-9 depression diagnostic scale [35], a 0-27 point scale where scores $\geq 10$ indicate the prevalence of likely depression [36]. To measure communication of HIV status we calculated the proportion of participants who reported always or often sharing their HIV status with clients before sex. To measure confidence in HIV status, participants were asked to report how likely it was, on a 1-10 ladder scale (10 being very likely), that they currently had HIV. If participants reported a 1 or a 10, we categorized them as confident in their HIV status. All pathway variables were self-reported and none were pre-specified for secondary analysis [25].

We also measured HIV testing mechanisms upstream of these pathways, including the proportion of FSWs who received/collected at least one HIV self-test kits, the proportion of FSWs who gave at an HIV self-test to others, the proportion of FSWs who tested for HIV since the start of the study.

\section{Statistical Analysis}

All statistical models were intention-to-treat, complete case analyses conducted at the unit of the individual [37-39]. We estimated risk differences at 1 and 4 months for the sexual behaviors outcomes and at 4 months for the pathway variables using generalized linear regression models with a fixed effect for study arm and a random effect for peer educator. We reported mean differences for the count outcomes and percentage point (PP) differences for the binary outcomes. We chose linear regression models for our primary analyses because they generate risk differences, which are easier to interpret than risk ratios.

In addition to the primary analyses, we conducted three sensitivity analyses. First, we calculated incident risk ratios for the count outcomes and risk ratios for the binary outcomes using mixed-effects generalized linear models (Poisson distribution, log link, and robust standard error) with a fixed effect for study arm and random effect for peer education. We choose to use modified Poisson models, like those used in the primary trial paper [7, 40], over log-binomial models because they generate similar outcomes and converge more easily when study results are relatively common [40]. Second, we pooled the sexual behavior outcomes across the two HIV self-testing intervention arms and compared these pooled outcomes with those from the standardof-care arm at 1 month and at 4 months using the generalized linear models that we used in the main analysis. Third, we conducted sub-group analyses where we explored the effect of the different HIV (self-) testing delivery models on sexual behavior outcomes among participants who selfreported testing HIV-negative and among participants who self-reported testing HIV-positive at their last HIV test at 1 month and at 4 months, again using the generalized linear models that we used in the main analysis.

We used Stata 13.1 (College Station, TX, USA) for all analyses. All statistical tests were two-sided with $p<0.05$ considered statistically significant.

\section{Results}

From October to November 2016, research assistants screened 1587 potential participants by phone and then 977 of these participants in-person. A total of 960 participants were enrolled and randomized: 296 (37 participant-peer educator groups) to the direct provision arm, 336 [42] to the facility collection arm, and 328 [41] to the standard-ofcare arm (Fig. 2) [7]. At 1 month 96\% of participant were retained in the study and at 4 months $90 \%$ of study participants were retained in the study.

The participants' socio-demographic characteristics and self-reported sexual behaviors at baseline did not differ across study arms (Table 1). The median age of participants was 28 years [interquartile range (IQR) 24-32 years]. The majority of participants reported less than 9 years of education (53.8\%), tested for HIV in the past 12 months (65.6\%), and reported having non-client sexual partners (59.1\%).

Participants' sexual behaviors by study arm at 1 month and at 4 months are shown in Table 2, while the effect size estimates (mean differences and PP changes) are shown in Fig. 3. The different HIV self-testing delivery models did not affect FSWs' average number of clients per night at 1 month and at 4 months, nor did they affect FSWs' inconsistent condom use with clients at 4 months. At 1 month, participants in the HIV self-testing facility collection arm were 8.8 PPs more likely to inconsistently use condoms with clients (95\% CI 1.3 to $16.3, p=0.02$ ) compared to those in the standard-of-care arm, but there were no statistically significant differences in this outcome among participants in the HIV self-testing facility collection arm compared to the standard-of-care arm at 4 months (PP 1.1, 95\% CI - 7.9 to $10.1, p=0.81$ ). 
Fig. 2 Participant recruitment, eligibility, randomization and follow-up. HIVST HIV self-test, $k$ clusters, $L T F U$ loss to followup, mos months

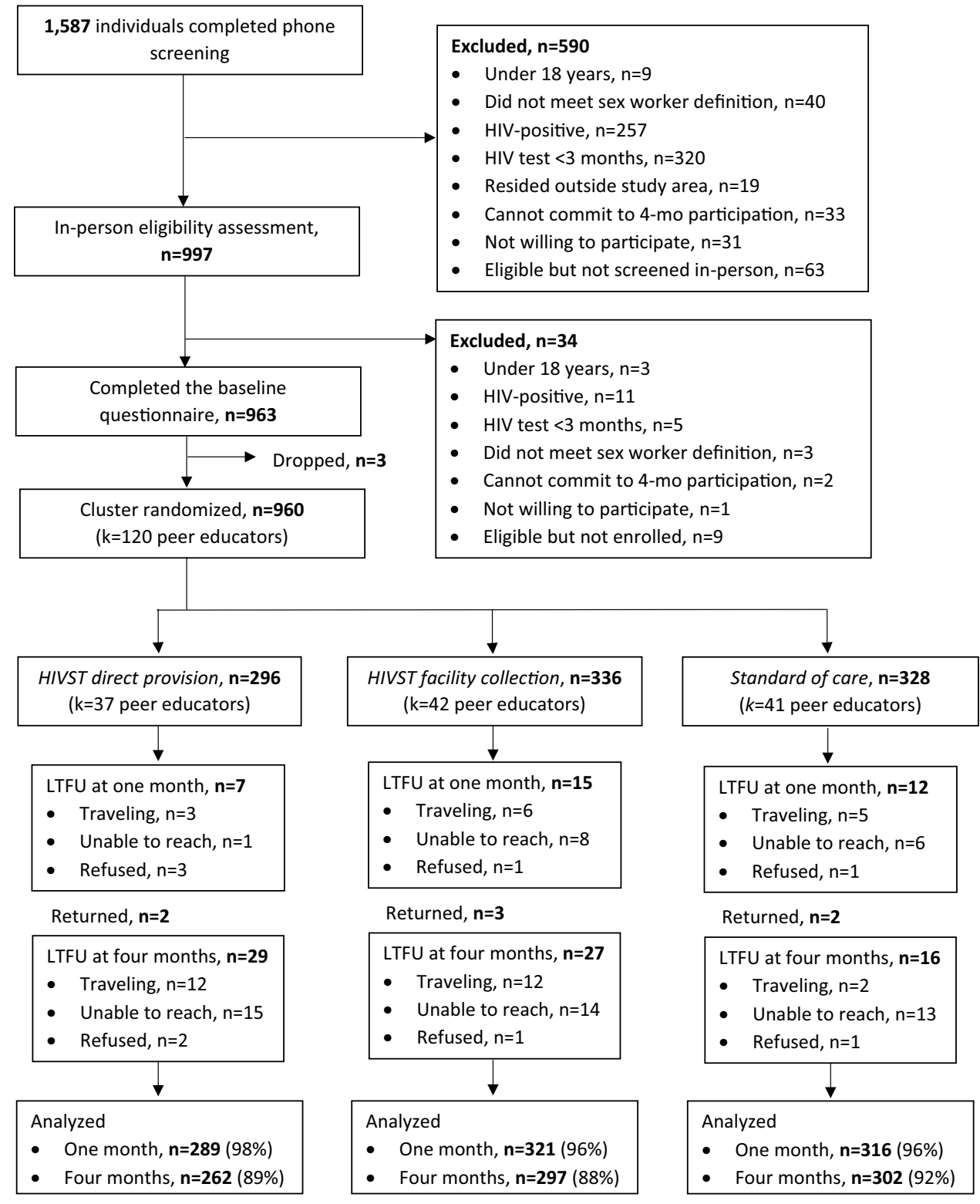

The different HIV self-testing delivery models did not affect FSWs' number of non-client sexual partners in the past month nor their inconsistent condom use with non-client sexual partners at 1 month and at 4 months (Table 2; Fig. 3).

Table 3 describes the HIV self-testing mechanisms and the variables associated with potential pathways through which HIV self-testing might affect FSWs' sexual behaviors. At 4 months, almost all participants in the HIV intervention arms received at least one HIV self-test, only a few participants gave an HIV self-test to a client, friend, or family member, and the vast majority of study participants across the study arms tested for HIV. As reported in Ortblad et al., the participants in HIV self-testing intervention arms were significantly more likely to test for HIV than those in the standard-of-care arm [7].
There were largely no statistically significant differences across study arms in any of the potential pathway variables: the proportion participants who of reported always using a condom with clients when they wanted and always or often asked clients to share their HIV status (empowerment), the proportion participants who were categorized as not likely depressed (hope), the proportion participants who reported always or often sharing their HIV status with clients (HIV status communication), and the proportion participants who were categorized as confident in their HIV status (confidence in HIV status). While more participants reported not being depressed in the HIV self-testing direct provision arm compared to the standard-of-care arm at 4 months (PP $10.3,95 \% \mathrm{CI}-0.1$ to $20.7, p=0.05$ ), this was only of borderline significance. 
Table 1 Participants' socio-demographic characteristics at baseline

Direct provision $(\mathrm{N}=296) \quad$ Facility collec- $\quad$ Standard-of-care $(\mathrm{N}=328) \quad$ Total $(\mathrm{N}=960)$ tion $(\mathrm{N}=336)$

\begin{tabular}{|c|c|c|c|c|}
\hline \multicolumn{5}{|l|}{ Characteristics } \\
\hline Age (med, IQR) & $28(24$ to 32$)$ & $28(25$ to 32$)$ & $28(24$ to 32$)$ & $28(24$ to 32$)$ \\
\hline \multicolumn{5}{|l|}{ Education } \\
\hline No formal & $24(8.1 \%)$ & $35(10.4 \%)$ & $20(6.1 \%)$ & $79(8.2 \%)$ \\
\hline Primary/junior & $121(40.9 \%)$ & $155(46.1 \%)$ & $161(49.1 \%)$ & $437(45.5 \%)$ \\
\hline Secondary & $143(48.3 \%)$ & $136(40.5 \%)$ & $144(43.9 \%)$ & $423(44.1 \%)$ \\
\hline Vocational & $2(0.7 \%)$ & $6(1.8 \%)$ & 0 & $8(0.8 \%)$ \\
\hline Tertiary & $6(2.0 \%)$ & $4(1.2 \%)$ & $3(1.0 \%)$ & $13(1.4 \%)$ \\
\hline \multicolumn{5}{|l|}{ Monthly income, USD ${ }^{\mathrm{a}}$} \\
\hline No income & $4(1.4 \%)$ & 0 & $1(0.3 \%)$ & $5(0.5 \%)$ \\
\hline$<\$ 35.67$ & $63(21.3 \%)$ & $76(22.9 \%)$ & $51(15.6 \%)$ & $190(19.9 \%)$ \\
\hline$\$ 35.67-\$ 74.32$ & $90(30.4 \%)$ & $117(35.2 \%)$ & $125(38.3 \%)$ & $332(34.8 \%)$ \\
\hline$\$ 74.32-\$ 148.64$ & $104(35.1 \%)$ & $107(32.2 \%)$ & $117(35.9 \%)$ & $328(34.4 \%)$ \\
\hline$>\$ 148.64$ & $35(11.9 \%)$ & $32(9.6 \%)$ & $32(9.8 \%)$ & $99(10.4 \%)$ \\
\hline \multicolumn{5}{|l|}{ Timing of last HIV test } \\
\hline$>3-6$ months & $123(37.5 \%)$ & $119(35.6 \%)$ & $108(36.7 \%)$ & $350(36.6 \%)$ \\
\hline$>6-12$ months & $102(31.1 \%)$ & $88(26.4 \%)$ & $90(30.6 \%)$ & $280(19.3 \%)$ \\
\hline$>12-24$ months & $42(12.8 \%)$ & $68(20.4 \%)$ & $46(15.7 \%)$ & $156(16.3 \%)$ \\
\hline$>24$ months & $42(12.8 \%)$ & $42(12.6 \%)$ & $30(10.2 \%)$ & $114(11.9 \%)$ \\
\hline Never tested & $19(5.8 \%)$ & $17(5.1 \%)$ & $20(6.8 \%)$ & $56(5.9 \%)$ \\
\hline \multicolumn{5}{|l|}{ Intimate partner violence, past 12 months } \\
\hline Physical & $102(34.5 \%)$ & $132(39.3 \%)$ & $115(35.3 \%)$ & $349(36.4 \%)$ \\
\hline Sexual & $89(30.1 \%)$ & $105(31.3 \%)$ & $94(28.8 \%)$ & $288(30.1 \%)$ \\
\hline \multicolumn{5}{|l|}{ Price for vaginal sex, USD (mean, sd) } \\
\hline With a condom & $\$ 3.77(\$ 3.99)$ & $\$ 2.98(\$ 2.74)$ & $\$ 3.04(\$ 3.13)$ & $\$ 3.24(\$ 3.31)$ \\
\hline Without a condom & $\$ 10.14(\$ 10.36)$ & $\$ 8.40(\$ 6.73)$ & $\$ 11.58(\$ 16.01)$ & $\$ 9.94(\$ 11.46)$ \\
\hline Have non-client partners & $120(61.5 \%)$ & $125(57.1 \%)$ & $133(58.9 \%)$ & $378(59.1 \%)$ \\
\hline Average number of clients/night (mean, sd) & $5.7(3.1)$ & $5.9(3.4)$ & $6.1(4.6)$ & $5.9(3.8)$ \\
\hline Inconsistent condom use with clients ${ }^{\mathrm{b}}$ & $125(42.5 \%)$ & $141(42.2 \%)$ & $122(37.4 \%)$ & $388(40.7 \%)$ \\
\hline Number of non-clients, past month (mean, sd) & $1.8(2.7)$ & $1.6(2.3)$ & $1.6(2.8)$ & $1.6(2.6)$ \\
\hline Inconsistent condom use with non-clients ${ }^{\mathrm{c}}$ & $157(54.9 \%)$ & $167(51.5 \%)$ & $165(51.2 \%)$ & $489(52.5 \%)$ \\
\hline
\end{tabular}

$N$ total number of participants, med median, IQR interquartile range, $s d$ standard deviation

a Price categories in US dollars (USD), $10^{\text {th }}$ October, 2016 exchange rate ( 1 USD = 3363.85 Ugandan Shillings)

${ }^{b}$ Defined as not using a condom with at least one client on an average working night

${ }^{c}$ Defined as never using a condom with at least one non-client sexual partner in the past month

In our sensitivity analyses measuring risk ratios instead of risk differences, HIV self-testing did not significantly affect FSWs' sexual behaviors at 1 month and at 4 months (Appendix Table 4). Similarly, when we pooled sexual behaviors outcomes across the HIV self-testing arms and compared outcomes from this pooled arm with those from the standard-ofcare arm, HIV self-testing did not significantly affect sexual behaviors at 1 months and at 4 months (Appendix Tables 5, 6).

In the sub-group analyses among participants who selfreported testing $H I V$-negative and among those who selfreported testing $H I V$-positive at their last test, the different HIV self-testing delivery models largely had no effect on
FSWs' sexual behaviors at 1 month and at 4 months compared to referral to standard HIV testing services (Appendix Tables 7, 8). The only statistically significant difference was among participants who self-reported testing HIV-positive in the direct provision HIV self-testing arm. At 1 month, inconsistent condom use with clients was significantly lower among these participants compared to participants who selfreported testing HIV-positive in the facility collection arm (PP $-17.5,95 \% \mathrm{CI}-33.8$ to $-1.2, p=0.04$ ), but these differences did not persist at 4 months (Appendix Table 8).

Two adverse events related to HIV self-testing were reported over the duration of the trial: intimate partner 
Table 2 Participants' sexual behaviors by study arm at 1 month and at 4 months

\begin{tabular}{|c|c|c|c|c|c|c|}
\hline \multirow[b]{2}{*}{ Outcomes } & \multicolumn{3}{|l|}{ One month } & \multicolumn{3}{|l|}{ Four months } \\
\hline & Direct provision & Facility collection & Standard-of-care & Direct provision & Facility collection & Standard-of-care \\
\hline \multicolumn{7}{|l|}{ Clients } \\
\hline $\begin{array}{l}\text { Average number clients/night } \\
\text { (mean, sd) }\end{array}$ & $5.5(3.1)$ & $5.3(2.8)$ & $5.6(4.2)$ & $5.6(3.4)$ & $5.3(3.1)$ & $5.9(4.0)$ \\
\hline $\begin{array}{l}\text { Inconsistent condom use }{ }^{\mathrm{a}} \\
(n / N, \%)\end{array}$ & 60/287 (20.9) & 93/321 (29.0) & $57 / 314(18.2)$ & $87 / 262(33.2)$ & 95/295 (32.2) & $82 / 299(27.4)$ \\
\hline \multicolumn{7}{|l|}{ Non-clients } \\
\hline $\begin{array}{l}\text { Number non-clients, past } \\
\text { month (mean, sd) }\end{array}$ & $0.8(0.8)$ & $0.8(0.9)$ & $0.9(0.9)$ & $0.8(0.9)$ & $0.8(0.9)$ & $0.9(0.9)$ \\
\hline $\begin{array}{l}\text { Inconsistent condom use }{ }^{\mathrm{b}} \\
(n / N, \%)\end{array}$ & $129 / 286(45.1)$ & $146 / 313(46.7)$ & $153 / 310(49.4)$ & $124 / 261(47.5)$ & $155 / 297(52.2)$ & $156 / 300(52.0)$ \\
\hline
\end{tabular}

$n$ number of participants reporting outcome, $N$ total number of participants, $s d$ standard deviation

${ }^{a}$ Defined as not using a condom with at least one client on an average working night

${ }^{b}$ Defined as never using a condom with at least one non-client sexual partner in the past month

violence following discovery of an HIV self-test, and mental distress from a perceived HIV-positive self-test result (the participant tested HIV-negative at a healthcare facility) [7].

\section{Discussion}

We tested the causal effects of two HIV self-testing delivery models on FSWs' sexual risk-taking. Neither the direct delivery of HIV self-tests nor the facility collection of HIV self-tests affected FSWs' sexual behaviors with client and non-client sexual partners compared to referral to standardof-care HIV testing services in urban Uganda. Our study adds to the emerging evidence on the effects of HIV selftesting on sexual behaviors [41-43].

Understanding the effect of HIV self-testing-delivered by different approaches-on behaviors directly related to the acquisition and transmission of HIV is important so that we understand the full implications of this testing technology. This understanding takes on particular significance as government in several sub-Saharan African countries are implementing or considering national scale-up of HIV self-testing as one routine testing option [23]. Our findings demonstrate no increase in sexual risk-taking among FSWs in response to the delivery of HIV self-tests. Routine policies for HIV self-testing are likely a safe component of comprehensive HIV testing and prevention strategies for FSWs. As HIV self-testing is scaled up to the national level, accompanying research should identify approaches to deliver HIV selftesting in ways that reduce sexual risk and increase access to other HIV interventions, including HIV pre-exposure prophylaxis and treatment-as-prevention.

Unlike the prior studies on this topic-two among men who have sex with men (MSM) in high-incomes settings
$[17,18]$ and one among Zambian FSWs [19]—-this study did not find that delivery of HIV self-testing reduced FSWs' HIV sexual risk-taking behaviors. It is immediately obvious that FSWs in Uganda are a very different population from MSM in high-income countries [44, 45] and might thus react differently to receiving HIV self-tests. For instance, MSM may have more power over their sex lives than FSWs in sub-Saharan Africa [46, 47], who may not be able to act on changes in their ability to test for HIV and the information resulting from HIV testing.

It is less obvious why our findings here differ from those in the study among FSWs in Zambian transit towns. However, there is significant variation in FSW populations globally in regards to the locations in which they work and live, their type of clientele, and their risk of HIV acquisition [48, 49]. For instance, compared to the FSWs in the Zambian study, the FSWs in this study worked in more urban environments and consequently reported a greater number of clients on an average working night $[6,7]$. As a result, the FSWs in our study might have had more casual versus steady clients compared to the FSWs in Zambia and this may have affected their ability to negotiate condom use. The risk of HIV transmission per commercial sex act is also greater in Zambia compared to Uganda as a result of higher population HIV prevalence [22, 50]. The FSWs in Zambia may thus have been more concerned about acquiring HIV compared to those in Uganda, and thus engaged in differential HIV sexual risk-taking behaviors as a result of HIV self-testing.

Jointly with this previous study, however, our study in a very different FSW population supports the policy recommendation that HIV self-testing is safe regarding its effects on sexual behavior. These studies suggest that concerns about HIV self-testing leading to increased sexual risking taking are unlikely to be true and thus should not be a reason 


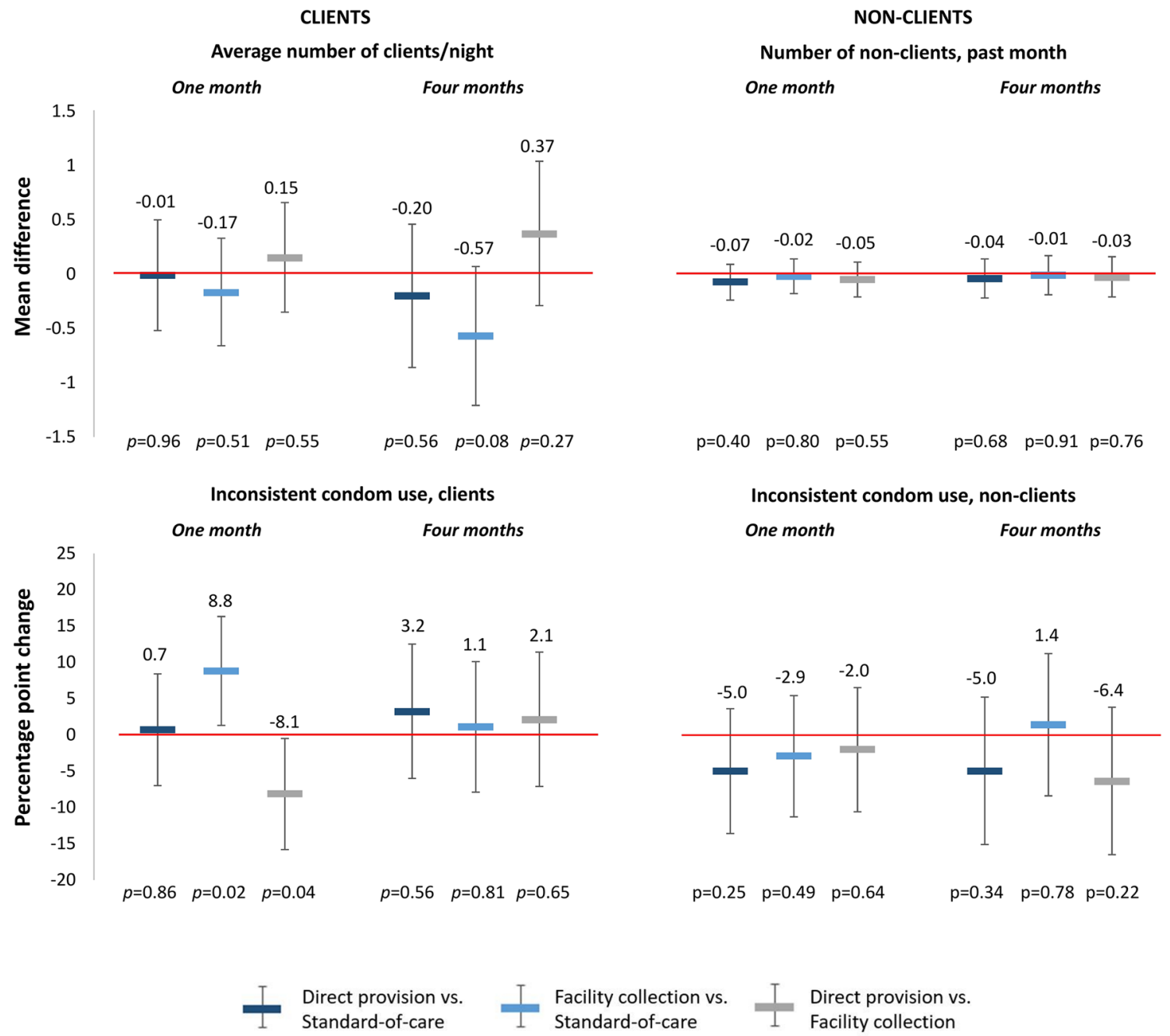

Fig. 3 The effect of the different HIV self-testing delivery models on FSWs' sexual behaviors with client and non-client sexual partners at 1 month and 4 months. Inconsistent condom use with clients was defined as not using a condom with at least one client on an average working night. Inconsistent condom use with non-clients was defined

for failing to make HIV self-tests available to FSWs in subSaharan Africa.

None of the pathways through which we hypothesized that the delivery of HIV self-tests might affect FSWs' sexual behaviors were affected by the HIV self-testing interventions, which may further explain why we found no differences in FSWs' HIV risk-related sexual behaviors by study arm. Even though significantly more FSWs in the HIV selftesting intervention arms tested for HIV since the start of the study [7], there were no differences in FSWs' empowerment, hope, HIV status communication, and knowledge of HIV status across study arms. The delivery of HIV self-tests may not have affected these pathway variables because FSWs may have little power within their sexual relationships with clients to negotiate the use of condom [46, 47]. as never using a condom with at least one non-client sexual partner in the past month. Comparisons between study arms: direct provision versus standard-of-care (dark blue), facility collection versus standard-of-care (light blue), direct provision versus facility collection (gray) (Color figure online)

Additionally, the prevalence of sexual and intimate partner violence among FSWs in this study was high and FSWs' economic incentives for the provision of condomless sex were large. HIV self-testing may not have changed FSWs' knowledge of HIV status in this study because the majority of participants had tested for HIV in the past year at baseline and thus may already have had a good idea of their HIV status. It is also possible that the FSWs who HIV self-tested may not have believed the result of a test that used oral-fluid instead of blood or may not have known how to interpret the self-test result [51].

Our study has a number of strengths. It is one of a few studies to explore the effect of HIV self-testing delivery models on sexual risk-taking behaviors [17-19] and focuses on a population that is a priority for HIV 
Table 3 Pathways through with HIV self-testing might affect FSWs' sexual behaviors at 4 months

\begin{tabular}{|c|c|c|c|c|c|c|c|c|c|}
\hline \multirow[t]{3}{*}{ Outcomes } & \multicolumn{3}{|c|}{ Percentage of participants } & \multicolumn{6}{|c|}{ Effect size estimates } \\
\hline & \multirow[t]{2}{*}{$\begin{array}{l}\text { Direct provi- } \\
\text { sion }\end{array}$} & \multirow[t]{2}{*}{$\begin{array}{l}\text { Facility collec- } \\
\text { tion }\end{array}$} & \multirow[t]{2}{*}{$\begin{array}{l}\text { Standard-of- } \\
\text { care }\end{array}$} & \multicolumn{2}{|c|}{$\begin{array}{l}\text { Direct provision versus } \\
\text { Standard-of-care }\end{array}$} & \multicolumn{2}{|c|}{$\begin{array}{l}\text { Facility collection versus } \\
\text { Standard-of-care }\end{array}$} & \multicolumn{2}{|c|}{$\begin{array}{l}\text { Direct provision } \\
\text { versus facility col- } \\
\text { lection }\end{array}$} \\
\hline & & & & $\mathrm{PP}^{\mathrm{a}}(95 \% \mathrm{CI})$ & $p$ & $\mathrm{PP}^{\mathrm{a}}(95 \% \mathrm{CI})$ & $p$ & $\mathrm{PP}^{\mathrm{a}}(95 \% \mathrm{CI})$ & $p$ \\
\hline \multicolumn{10}{|l|}{ Mechanisms } \\
\hline $\begin{array}{l}\text { Received/col- } \\
\text { lected HIV } \\
\text { self-test }^{\mathrm{b}}\end{array}$ & $\begin{array}{l}260 / 262 \\
(99.2 \%)\end{array}$ & $\begin{array}{l}283 / 297 \\
(95.3 \%)\end{array}$ & $\mathrm{n} / \mathrm{a}$ & $\mathrm{n} / \mathrm{a}$ & & $\mathrm{n} / \mathrm{a}$ & & $3.8(1.1$ to 6.5$)$ & 0.01 \\
\hline $\begin{array}{l}\text { Gave an HIV } \\
\text { self-test to } \\
\text { others }^{c}\end{array}$ & $4 / 262(1.5 \%)$ & $1 / 297(0.3 \%)$ & $\mathrm{n} / \mathrm{a}$ & $\mathrm{n} / \mathrm{a}$ & & $\mathrm{n} / \mathrm{a}$ & & $\begin{array}{l}1.2(-0.1 \text { to } \\
2.5)\end{array}$ & 0.07 \\
\hline $\begin{array}{l}\text { Tested for } \\
\text { HIV }^{\mathrm{d}}\end{array}$ & $\begin{array}{l}261 / 262 \\
(99.6 \%)\end{array}$ & $\begin{array}{l}288 / 297 \\
(97.0 \%)\end{array}$ & $\begin{array}{l}263 / 302 \\
(87.1 \%)\end{array}$ & $\begin{array}{l}12.9(7.6 \text { to } \\
18.2)\end{array}$ & $<0.001$ & $\begin{array}{l}10.3(5.2 \text { to } \\
15.4)\end{array}$ & $<0.001$ & $\begin{array}{l}2.6(-2.7 \text { to } \\
7.8)\end{array}$ & 0.34 \\
\hline \multicolumn{10}{|l|}{$\begin{array}{l}\text { Pathway vari- } \\
\text { ables }\end{array}$} \\
\hline \multicolumn{10}{|l|}{$\begin{array}{l}\text { Empower- } \\
\text { ment }\end{array}$} \\
\hline $\begin{array}{l}\text { Always } \\
\text { used a } \\
\text { condom } \\
\text { with cli- } \\
\text { ents when } \\
\text { want to }\end{array}$ & $\begin{array}{l}203 / 262 \\
(77.5 \%)\end{array}$ & $\begin{array}{l}226 / 297 \\
(76.1 \%)\end{array}$ & $\begin{array}{l}225 / 301 \\
(74.8 \%)\end{array}$ & $\begin{array}{l}2.7(-6.0 \text { to } \\
11.3)\end{array}$ & 0.55 & $\begin{array}{l}1.4(-7.0 \text { to } \\
9.7)\end{array}$ & 0.75 & $\begin{array}{l}1.3(-7.3 \text { to } \\
9.9)\end{array}$ & 0.77 \\
\hline $\begin{array}{l}\text { Always/ } \\
\text { often ask } \\
\text { client to } \\
\text { share HIV } \\
\text { status }\end{array}$ & $16 / 262(6.1 \%)$ & $17 / 297(5.7 \%)$ & $21 / 302(7.0 \%)$ & $\begin{array}{l}-0.7(-5.6 \text { to } \\
4.3)\end{array}$ & 0.79 & $\begin{array}{l}-1.2(-6.0 \text { to } \\
3.6)\end{array}$ & 0.63 & $\begin{array}{l}0.5(-4.4 \text { to } \\
5.4)\end{array}$ & 0.84 \\
\hline \multicolumn{10}{|l|}{ Hope } \\
\hline $\begin{array}{l}\text { Not } \\
\text { depressed } \\
(\text { PHQ-9) }\end{array}$ & $\begin{array}{l}208 / 262 \\
(79.4 \%)\end{array}$ & $\begin{array}{l}214 / 297 \\
\quad(72.1 \%)\end{array}$ & $\begin{array}{l}206 / 302 \\
(68.2 \%)\end{array}$ & $\begin{array}{l}10.3(-0.1 \text { to } \\
20.7)\end{array}$ & 0.05 & $\begin{array}{l}4.0(-6.0 \text { to } \\
14.1)\end{array}$ & 0.43 & $\begin{array}{l}6.3(-4.1 \text { to } \\
16.6)\end{array}$ & 0.24 \\
\hline \multicolumn{10}{|l|}{$\begin{array}{l}\text { Communica- } \\
\text { tion of HIV } \\
\text { status }\end{array}$} \\
\hline $\begin{array}{l}\text { Always/ } \\
\text { often } \\
\text { share HIV } \\
\text { status } \\
\text { with client }\end{array}$ & $30 / 260(11.5 \%)$ & $20 / 296(6.8 \%)$ & $22 / 300(7.3 \%)$ & $\begin{array}{l}4.3(-2.3 \text { to } \\
11.0)\end{array}$ & 0.20 & $\begin{array}{l}-0.7(-7.2 \text { to } \\
5.7)\end{array}$ & 0.82 & $\begin{array}{l}5.1(-1.6 \text { to } \\
11.7)\end{array}$ & 0.14 \\
\hline \multicolumn{10}{|l|}{$\begin{array}{l}\text { Confidence in } \\
\text { HIV knowl- } \\
\text { edge }\end{array}$} \\
\hline $\begin{array}{l}\text { Confident } \\
\text { in HIV } \\
\text { status }^{\mathrm{g}}\end{array}$ & $\begin{array}{l}126 / 262 \\
(48.1 \%)\end{array}$ & $\begin{array}{l}132 / 297 \\
(44.4 \%)\end{array}$ & $\begin{array}{l}148 / 302 \\
(49.0 \%)\end{array}$ & $\begin{array}{l}-1.4(-13.8 \\
\text { to } 11.1)\end{array}$ & 0.83 & $\begin{array}{l}-4.6(-16.6 \\
\text { to } 7.5)\end{array}$ & 0.46 & $\begin{array}{l}3.2(-9.2 \text { to } \\
15.6)\end{array}$ & 0.61 \\
\hline
\end{tabular}

$P P$ percentage point change, $C I$ confidence interval, $p p$ value

${ }^{a}$ Linear models with study arm fixed effects and peer educator random effects

${ }^{b}$ Participants reported receiving or collecting at least one HIV self-test from their peer educator or the healthcare facility

${ }^{c}$ Participants reported not using at least one of their HIV self-tests to test themselves and reported giving the self-test to a client, friend, or family member ${ }^{\mathrm{d}}$ Any HIV testing reported since the start of the study (Ortblad et al. PLoS Med [7])

${ }^{\text {e}}$ Participants were asked if there was a time in the past month when they wanted to use a condom during sexual intercourse with a client and did not ${ }^{\mathrm{f}}$ Participants were categorized as not depressed (scores $\left.<10\right)$ using the PHQ-9 scale $(0-27$ points)

${ }^{\mathrm{g}}$ Participants report likelihood that they currently have HIV as 1 (very unlikely) or 10 (very likely) on a 1-10 ladder 
prevention interventions. Our study further has causal strength, because it is a randomized controlled trial. Additionally, the study outlines and explores different pathways through which HIV self-testing delivery models might affect FSWs' sexual behaviors.

Our study also has several limitations. First, all sexual behaviors outcomes were self-reported by participants and subject to recall and social desirability bias, a common limitation of most studies of sexual behavior. Direct measures of sexual behavior are not feasible and biomarkers for sexual activity are still not established for routine population-based application because their performance is poor and they are expensive and difficult to collect [52, 53]. In the absence of direct or biological measures, selfreported sexual behavior data is the best available option, despite its obvious shortcomings.

Second, the follow-up period of the trial, 4 months, was a relatively short duration; preventing us from measuring the longer term effects of HIV self-testing delivery models on FSWs' sexual behaviors. Third, the trial was not specifically powered to measure differences in sexual behaviors outcomes across study arms, contributing to greater uncertainty around the effect size estimates, especially in the HIV status sub-group analyses. All of our effect size estimates, however, were close to zero and had narrow confidence intervals, suggesting the null effect of HIV self-testing delivery models on FSWs' sexual behaviors. Fourth, we only collected measurements of the pathway variables at the end of the study (4 months) and thus were unable to assess how the intervention effected these variables at other time points.

Finally, due to the diversity of FSW populations, the generalizability of these results might be limited in settings outside urban Uganda. But taken together with the previous evidence in a very different FSW population in Zambian transit towns, a robust conclusion appears to be emerging: HIV self-testing-delivered by different approaches and to different FSW populations-does not increase sexual risk taking.

\section{Conclusion}

We find that HIV self-testing does not increase sexual risktaking among FSWs. Routine policies for HIV self-testing are thus likely safe for this key population in the HIV response. As national governments in sub-Saharan Africa scale up HIV self-testing, accompanying research should identify approaches to deliver HIV self-testing in ways that reduce sexual risk and increase access to other HIV interventions.

Acknowledgements We would like to acknowledge all the study participants who took time participating in this study as well as the research assistants who took time collecting this data. We would additionally like to acknowledge the Administrative Staff at both the Uganda Health Marketing Group and International Research Consortium who kept the study on schedule, the study's Scientific Oversight Committee for participation in the interim report and monitoring adverse events, and the Ugandan Ministry of Health for assistance with necessary approvals. This study was funded by the International Initiative for Impact Evaluation (3ie). KFO was additionally supported by the National Institute of Allergy and Infectious Disease (T32-AI007535), the National Institute for Mental Health (R01-MH110296, PI: Heffron and R01-MH113572, PIs: Baeten/Ngure). JEH was supported in part by the National Institute of Health (K24-MH114732). CEO was supported in part by the National Institute on Drug Abuse (T32-DA013911) and the National Institute of Allergy and Mental Health (R25-MH083620). TB was funded by the Alexander von Humboldt Foundation through the Alexander von Humboldt Professorship endowed by the German Federal Ministry of Education and Research. He was also supported by the Wellcome Trust, the European Commission, the Clinton Health Access Initiative and NICHD of NIH (R01-HD084233), NIAID of NIH (R01-AI124389 and R01-AI112339) and FIC of NIH (D43-TW009775). For the remaining authors, none were declared. Oral HIV self-tests were obtained from OraSure Technologies at cost. The funders had no role in study design, data collection and analysis, decision to publish, or preparation of the manuscript.

Author Contribution KFO, CEO, MAM, JEH, JAS, and TB conceptualized the paper. KFO conducted the analysis and wrote the first draft. MAM, JEH, JAS, CEO and TB supervised the methodology. KFO, CEO, DKM, TN and AN oversaw study administration and the collection of quality data. All authors edited the draft and provided insights into the manuscript.

\section{Compliance with Ethical Standards}

Conflict of interest The authors of this study declare no competing interests.

OpenAccess This article is distributed under the terms of the Creative Commons Attribution 4.0 International License (http://creativeco mmons.org/licenses/by/4.0/), which permits unrestricted use, distribution, and reproduction in any medium, provided you give appropriate credit to the original author(s) and the source, provide a link to the Creative Commons license, and indicate if changes were made.

\section{Appendix}

See Tables 4, 5, 6, 7 and 8 . 
Table 4 Sensitivity analysis 1: incident risk ratios and risk ratios of HIV self-testing on risky sexual behaviors among participants self-reporting HIV-negative status at 1 month and 4 months

\begin{tabular}{|c|c|c|c|c|c|c|}
\hline \multirow[t]{2}{*}{ Outcomes } & \multicolumn{2}{|l|}{$\begin{array}{l}\text { Direct provision versus } \\
\text { Standard-of-care }\end{array}$} & \multicolumn{2}{|c|}{$\begin{array}{l}\text { Facility collection versus } \\
\text { Standard-of-care }\end{array}$} & \multicolumn{2}{|l|}{$\begin{array}{l}\text { Direct provision versus } \\
\text { facility collection }\end{array}$} \\
\hline & Risk ratio $^{\mathrm{a}}(95 \% \mathrm{CI})$ & $p$ & Risk ratio $^{\mathrm{a}}(95 \% \mathrm{CI})$ & $p$ & Risk ratio $^{\mathrm{a}}(95 \% \mathrm{CI})$ & $p$ \\
\hline \multicolumn{7}{|l|}{ One month } \\
\hline \multicolumn{7}{|l|}{ Clients } \\
\hline Avg \# clients/night (IRR) & $0.98(0.85$ to 1.23$)$ & 0.74 & $0.97(0.85$ to 1.10$)$ & 0.62 & $1.01(0.89$ to 1.15$)$ & 0.89 \\
\hline Inconsistent condom use ${ }^{\mathrm{b}}(\mathrm{RR})$ & $1.15(0.69$ to 1.90$)$ & 0.59 & $1.64(1.05$ to 2.54$)$ & 0.03 & $0.70(0.44$ to 1.12$)$ & 0.14 \\
\hline \multicolumn{7}{|l|}{ Non-clients } \\
\hline \# Non-clients, past month (IRR) & $0.93(0.74$ to 1.17$)$ & 0.55 & $0.96(0.76$ to 1.21$)$ & 0.73 & 0.97 (0.76 to 1.24$)$ & 0.82 \\
\hline Inconsistent condom use ${ }^{c}(\mathrm{RR})$ & $0.91(0.74$ to 1.13$)$ & 0.40 & $0.95(0.78$ to 1.15$)$ & 0.57 & $0.97(0.77$ to 1.21$)$ & 0.77 \\
\hline \multicolumn{7}{|l|}{ Four months } \\
\hline \multicolumn{7}{|l|}{ Clients } \\
\hline Avg \# clients/night (IRR) & $0.93(0.79$ to 1.10$)$ & 0.40 & $0.89(0.78$ to 1.03$)$ & 0.12 & $1.04(0.90$ to 1.21$)$ & 0.58 \\
\hline Inconsistent condom use ${ }^{\mathrm{b}}(\mathrm{RR})$ & $1.20(0.80$ to 1.80$)$ & 0.37 & $1.16(0.78$ to 1.72$)$ & 0.46 & $1.04(0.69$ to 1.56$)$ & 0.87 \\
\hline \multicolumn{7}{|l|}{ Non-clients } \\
\hline \# Non-clients, past month (IRR) & $0.94(0.73$ to 1.22$)$ & 0.64 & $0.99(0.80$ to 1.23$)$ & 0.95 & $0.95(0.73$ to 1.22$)$ & 0.68 \\
\hline Inconsistent condom use ${ }^{c}(\mathrm{RR})$ & $0.91(0.72$ to 1.16$)$ & 0.44 & $1.00(0.81$ to 1.23$)$ & 1.00 & $0.91(0.71$ to 1.16$)$ & 0.45 \\
\hline
\end{tabular}

$R R$ risk ratio, $I R R$ incidence risk ratio, $C I$ confidence interval, $p$ p-value

${ }^{a}$ Linear models with study arm fixed effects and peer educator random effects, adjusted for sexual behavior at baseline

${ }^{b}$ Defined as not using a condom with at least one client on an average working night

${ }^{\mathrm{c}}$ Defined as never using a condom with at least one non-client sexual partner in the past month

Table 5 Sensitivity analysis 2: risk differences of pooled HIV self-testing arms on risky sexual behaviors at 1 and 4 months

\begin{tabular}{|c|c|c|c|c|}
\hline Outcomes & $\begin{array}{l}n / N(\%) \text { or mean }(\mathrm{sd}) \\
\text { Pooled HIVST arms }\end{array}$ & Standard-of-care & Risk differences $^{\mathrm{a}}(95 \% \mathrm{CI})$ & $p$ \\
\hline \multicolumn{5}{|l|}{ One month } \\
\hline \multicolumn{5}{|l|}{ Clients } \\
\hline Avg \# clients/night (mean, sd; MD) & $5.4(2.9)$ & $5.6(4.2)$ & $-0.09(-0.53$ to 0.34$)$ & 0.67 \\
\hline Inconsistent condom use ${ }^{\mathrm{b}}(n / N ; \mathrm{PP})$ & $153 / 608(25.2 \%)$ & $57 / 314(18.2 \%)$ & $5.0(-1.7$ to 11.7$)$ & 0.14 \\
\hline \multicolumn{5}{|l|}{ Non-clients } \\
\hline \# Non-clients, past month (mean, sd; MD) & $0.8(0.9)$ & $0.9(0.9)$ & $-0.04(-0.18$ to 0.10$)$ & 0.53 \\
\hline Inconsistent condom use ${ }^{\mathrm{c}}(n / N ; \mathrm{PP})$ & $275 / 599(45.9 \%)$ & $153 / 310(49.4 \%)$ & $-3.9(-11.2$ to 3.4$)$ & 0.29 \\
\hline \multicolumn{5}{|l|}{ Four months } \\
\hline \multicolumn{5}{|l|}{ Clients } \\
\hline Avg \# clients/night (mean, sd; MD) & $5.4(3.2)$ & $5.9(3.4)$ & $-0.40(-0.96$ to 0.17$)$ & 0.17 \\
\hline Inconsistent condom use $\mathrm{e}^{\mathrm{b}}(n / N ; \mathrm{PP})$ & $182 / 557(32.7 \%)$ & $82 / 299(27.4 \%)$ & $2.1(-5.8$ to 9.9$)$ & 0.60 \\
\hline \multicolumn{5}{|l|}{ Non-clients } \\
\hline \# Non-clients, past month (mean, sd; MD) & $0.8(0.9)$ & $0.9(0.9)$ & $-0.02(-0.18$ to 0.13$)$ & 0.77 \\
\hline Inconsistent condom use ${ }^{c}(n / N ; \mathrm{PP})$ & $279 / 558(50.0 \%)$ & $156 / 300(52.0 \%)$ & $-1.6(-10.2$ to 7.0$)$ & 0.72 \\
\hline
\end{tabular}

HIVST HIV self-testing, $n$ number of participants reporting outcome, $N$ total number of participants, $M D$ mean difference, $P P$ percentage point change, $C I$ confidence interval, $p$ p-value

${ }^{a}$ Linear models with study arm fixed effects and peer educator random effects, adjusted for sexual behavior at baseline

${ }^{\mathrm{b}}$ Defined as not using a condom with at least one client on an average working night

${ }^{c}$ Defined as never using a condom with at least one non-client sexual partner in the past month 
Table 6 Sensitivity analysis 2: participants' sexual behaviors by study arm by self-reported HIV status at 1 month and at 4 months

\begin{tabular}{|c|c|c|c|c|c|c|}
\hline \multirow[t]{2}{*}{ Outcomes } & \multicolumn{3}{|l|}{ One month } & \multicolumn{3}{|l|}{ Four months } \\
\hline & Direct provision & Facility collection & Standard-of-care & Direct provision & Facility collection & Standard-of-care \\
\hline \multicolumn{7}{|l|}{ Participants, HIV-negative $^{a}$} \\
\hline \multicolumn{7}{|l|}{ Clients } \\
\hline $\begin{array}{l}\text { Avg \# clients/night (mean, } \\
\text { sd) }\end{array}$ & $5.5(3.1)$ & $5.2(2.7)$ & $5.6(4.4)$ & $5.5(3.2)$ & $5.1(2.7)$ & $5.8(3.9)$ \\
\hline Inconsistent condom use $\mathrm{e}^{\mathrm{b}}$ & $50 / 239(20.9 \%)$ & $59 / 247(23.9 \%)$ & $46 / 262(17.6 \%)$ & $68 / 212(32.1 \%)$ & $60 / 207(29.0 \%)$ & $68 / 245(27.8 \%)$ \\
\hline \multicolumn{7}{|l|}{ Non-clients } \\
\hline $\begin{array}{l}\text { \# Non-clients, past month } \\
\text { (mean, sd) }\end{array}$ & $0.8(0.8)$ & $0.8(0.9)$ & $0.9(0.9)$ & $0.9(0.9)$ & $0.8(0.7)$ & $0.9(1.0)$ \\
\hline Inconsistent condom use $\mathrm{c}^{\mathrm{c}}$ & $115 / 238(48.3 \%)$ & $113 / 243(46.5 \%)$ & $127 / 258(49.2 \%)$ & $105 / 211(49.8 \%)$ & $104 / 208(50.0 \%)$ & $129 / 245(52.7 \%)$ \\
\hline \multicolumn{7}{|l|}{ Participants, HIV-positive ${ }^{\mathrm{a}}$} \\
\hline \multicolumn{7}{|l|}{ Clients } \\
\hline $\begin{array}{l}\text { Avg \# clients/night (mean, } \\
\text { sd) }\end{array}$ & $5.5(2.9)$ & $5.8(2.9)$ & $6.4(3.6)$ & $6.6(4.8)$ & $5.6(3.7)$ & $6.8(4.2)$ \\
\hline Inconsistent condom use $\mathrm{e}^{\mathrm{b}}$ & $7 / 38(18.4 \%)$ & $26 / 54(48.2 \%)$ & $9 / 38(23.7 \%)$ & $15 / 34(44.1 \%)$ & $26 / 65(40.0 \%)$ & $11 / 43(25.6 \%)$ \\
\hline \multicolumn{7}{|l|}{ Non-clients } \\
\hline $\begin{array}{l}\text { \# Non-clients, past month } \\
\text { (mean, sd) }\end{array}$ & $0.6(0.7)$ & $0.9(1.0)$ & $0.9(0.8)$ & $0.5(0.8)$ & $1.1(1.1)$ & $0.6(0.6)$ \\
\hline Inconsistent condom use $\mathrm{c}^{\mathrm{c}}$ & $10 / 38(26.3 \%)$ & $24 / 51(47.1 \%)$ & $19 / 37(51.4 \%)$ & $11 / 34(32.4 \%)$ & $36 / 66(54.6 \%)$ & $20 / 44(45.5 \%)$ \\
\hline
\end{tabular}

avg average, $s d$ standard deviation, mos months

${ }^{\text {a }}$ Self-reported results of last HIV test

${ }^{\mathrm{b}}$ Defined as not using a condom with at least one client on an average working night

${ }^{c}$ Defined as never using a condom with at least one non-client sexual partner in the past month

Table 7 Sensitivity analysis 3: risk differences of HIV self-testing on risky sexual behaviors among participants self-reporting HIV-negative status at 1 and 4 months

\begin{tabular}{|c|c|c|c|c|c|c|}
\hline \multirow[t]{2}{*}{ Outcomes } & \multicolumn{2}{|l|}{$\begin{array}{l}\text { Direct provision versus } \\
\text { standard-of-care }\end{array}$} & \multicolumn{2}{|l|}{$\begin{array}{l}\text { Facility collection versus } \\
\text { standard-of-care }\end{array}$} & \multicolumn{2}{|l|}{$\begin{array}{l}\text { Direct provision versus } \\
\text { facility collection }\end{array}$} \\
\hline & Risk difference $^{\mathrm{a}}(95 \% \mathrm{CI})$ & $p$ & Risk difference $^{\mathrm{a}}(95 \% \mathrm{CI})$ & $p$ & Risk difference $^{\mathrm{a}}(95 \% \mathrm{CI})$ & $p$ \\
\hline \multicolumn{7}{|l|}{ One month } \\
\hline \multicolumn{7}{|l|}{ Clients } \\
\hline Avg \# clients/night (MD) & $-0.06(-0.46$ to 0.57$)$ & 0.83 & $-0.21(-0.72$ to 0.29$)$ & 0.41 & $0.27(-0.25$ to 0.79$)$ & 0.31 \\
\hline Inconsistent condom use $\mathrm{e}^{\mathrm{b}}(\mathrm{PP})$ & $2.1(-5.7$ to 10.0$)$ & 0.60 & $6.1(-1.7$ to 13.9$)$ & 0.12 & $-4.0(-11.9$ to 4.0$)$ & 0.33 \\
\hline \multicolumn{7}{|l|}{ Non-clients } \\
\hline \# Non-clients, past month (MD) & $-0.05(-0.23$ to 0.13$)$ & 0.57 & $-0.02(-0.20$ to 0.16$)$ & 0.81 & $-0.03(-0.21$ to 0.15$)$ & 0.74 \\
\hline Inconsistent condom use ${ }^{c}(\mathrm{PP})$ & $-3.7(-13.1$ to 5.7$)$ & 0.44 & $-3.1(-12.4$ to 6.2$)$ & 0.51 & $-0.6(-10.1$ to 8.9$)$ & 0.90 \\
\hline \multicolumn{7}{|l|}{ Four months } \\
\hline \multicolumn{7}{|l|}{ Clients } \\
\hline Avg \# clients/night (MD) & $-0.26(-0.95$ to 0.44$)$ & 0.47 & $-0.69(-1.38$ to 0.00$)$ & 0.05 & $0.43(-0.28$ to 1.15$)$ & 0.23 \\
\hline Inconsistent condom use ${ }^{\mathrm{b}}(\mathrm{PP})$ & $1.3(-8.1$ to 10.7$)$ & 0.79 & $-0.2(-9.6$ to 9.1$)$ & 0.96 & $1.5(-8.1$ to 11.1$)$ & 0.75 \\
\hline \multicolumn{7}{|l|}{ Non-clients } \\
\hline \# Non-clients, past month (MD) & $-0.04(-0.22$ to 0.15$)$ & 0.70 & $-0.11(-0.30$ to 0.08$)$ & 0.24 & $0.07(-0.12$ to 0.27$)$ & 0.45 \\
\hline Inconsistent condom use ${ }^{c}(\mathrm{PP})$ & $-5.7(-16.3$ to 5.0$)$ & 0.30 & $-1.2(-11.8$ to 9.4$)$ & 0.82 & $-4.5(-15.5$ to 6.5$)$ & 0.42 \\
\hline
\end{tabular}

$M D$ mean difference, $P P$ percentage point difference, $C I$ confidence interval, $p$ p-value

${ }^{a}$ Linear models with study arm fixed effects and peer educator random effects, adjusted for sexual behavior at baseline

${ }^{\mathrm{b}}$ Defined as not using a condom with at least one client on an average working night

${ }^{c}$ Defined as never using a condom with at least one non-client sexual partner in the past month 
Table 8 Sensitivity analysis 3: risk differences of HIV self-testing on risky sexual behaviors among participants self-reporting HIV-positive status at 1 and 4 months

\begin{tabular}{|c|c|c|c|c|c|c|}
\hline \multirow[t]{2}{*}{ Outcomes } & \multicolumn{2}{|l|}{$\begin{array}{l}\text { Direct provision versus } \\
\text { standard-of-care }\end{array}$} & \multicolumn{2}{|l|}{$\begin{array}{l}\text { Facility collection versus } \\
\text { standard-of-care }\end{array}$} & \multicolumn{2}{|l|}{$\begin{array}{l}\text { Direct provision versus } \\
\text { facility collection }\end{array}$} \\
\hline & Risk differences $^{\mathrm{a}}(95 \% \mathrm{CI})$ & $p$ & Risk differences $^{\mathrm{a}}(95 \% \mathrm{CI})$ & $p$ & Risk differences $^{\mathrm{a}}(95 \% \mathrm{CI})$ & $p$ \\
\hline \multicolumn{7}{|l|}{ One month } \\
\hline \multicolumn{7}{|l|}{ Clients } \\
\hline Avg \# clients/night (MD) & $-0.73(-2.05$ to 0.58$)$ & 0.28 & $-0.34(-1.61$ to 0.94$)$ & 0.61 & $-0.40(-1.67$ to 0.88$)$ & 0.54 \\
\hline Inconsistent condom use $\mathrm{e}^{\mathrm{b}}(\mathrm{PP})$ & $-7.9(-25.2$ to 9.4$)$ & 0.37 & $9.6(-6.9$ to 26.2$)$ & 0.25 & $-17.5(-33.8$ to -1.2$)$ & 0.04 \\
\hline \multicolumn{7}{|l|}{ Non-clients } \\
\hline \# Non-clients, past month (MD) & $-0.22(-0.59$ to 0.16$)$ & 0.26 & $-0.03(-0.38$ to 0.32$)$ & 0.87 & $-0.19(-0.55$ to 0.17$)$ & 0.31 \\
\hline Inconsistent condom use ${ }^{c}(\mathrm{PP})$ & $-17.8(-40.2$ to -4.7$)$ & 0.12 & $-4.8(-25.8$ to 16.1$)$ & 0.65 & $-12.9(-34.2$ to 8.3$)$ & 0.23 \\
\hline \multicolumn{7}{|l|}{ Four months } \\
\hline \multicolumn{7}{|l|}{ Clients } \\
\hline Avg \# clients/night (MD) & $0.42(-1.15$ to 1.99$)$ & 0.60 & $-0.53(-1.86$ to 0.81$)$ & 0.44 & $0.95(-0.52$ to 2.42$)$ & 0.21 \\
\hline Inconsistent condom use ${ }^{\mathrm{b}}(\mathrm{PP})$ & $15.8(-3.4$ to 35.1$)$ & 0.11 & $3.5(-13.6$ to 20.6$)$ & 0.69 & $12.3(-5.7$ to 30.4$)$ & 0.18 \\
\hline \multicolumn{7}{|l|}{ Non-clients } \\
\hline \# Non-clients, past month (MD) & $-0.09(-0.52$ to 0.34$)$ & 0.68 & $0.27(-0.10$ to 0.65$)$ & 0.16 & $-0.36(-0.77$ to -0.04$)$ & 0.08 \\
\hline Inconsistent condom use ${ }^{c}(\mathrm{PP})$ & $-4.8(-28.3$ to 18.7$)$ & 0.69 & $7.6(-12.8$ to 27.9$)$ & 0.47 & $-12.4(-34.5$ to 9.7$)$ & 0.27 \\
\hline
\end{tabular}

$M D$ mean difference, $P P$ percentage point difference, $C I$ confidence interval, $p$ p-value

${ }^{a}$ Linear models with study arm fixed effects and peer educator random effects, adjusted for sexual behavior at baseline

${ }^{b}$ Defined as not using a condom with at least one client on an average working night

${ }^{\mathrm{c}}$ Defined as never using a condom with at least one non-client sexual partner in the past month

\section{References}

1. Masters SH, Agot K, Obonyo B, Mavedzenge SN, Maman S, Thirumurthy $\mathrm{H}$. Promoting partner testing and couples testing through secondary distribution of HIV self-tests: a randomized clinical trial. PLOS Med. 2016;13(11):e1002166.

2. Thirumurthy H, Masters SH, Mavedzenge SN, Maman S, Omanga E, Agot K. Promoting male partner HIV testing and safer sexual decision making through secondary distribution of self-tests by HIV-negative female sex workers and women receiving antenatal and post-partum care in Kenya: a cohort study. Lancet HIV. 2016;3(6):e266-74.

3. Wang Z, Lau JTF, Ip M, Ho SPY, Mo PKH, Latkin C, et al. A randomized controlled trial evaluating efficacy of promoting a home-based HIV self-testing with online counseling on increasing HIV testing among men who have sex with men. AIDS Behav. 2017. https://doi.org/10.1007/s10461-017-1887-2.

4. Katz D, Golden M, Hughes J, Farquhar. HIV self-testing increases HIV testing frequency among high-risk men who have sex with men: a randomized controlled trial. In: 8th Conference on HIV pathogenesis, treatment and prevention, 19-22 July 2015, Vancouver, Canada; 2015

5. Jamil MS, Prestage G, Fairley CK, Grulich AE, Smith KS, Chen $\mathrm{M}$, et al. Effect of availability of HIV self-testing on HIV testing frequency in gay and bisexual men at high risk of infection (FORTH): a waiting-list randomised controlled trial. Lancet HIV. 2017;4(6):e241-50.

6. Chanda M, Ortblad K, Mwale M, Chongo S, Kanchele C, Kamungoma N, et al. HIV self-testing among female sex workers in Zambia: a cluster randomized controlled trial. PLOS Med. 2017;14(11):e1002442.

7. Ortblad K, Kibuuka Musoke D, Ngabirano T, Nakidende A, Magoola J, Kayiira P, et al. Direct provision versus facility collection of HIV self-tests among female sex workers in Uganda: a cluster-randomized controlled health systems trial. PLOS Med. 2017;14(11):e1002458.

8. Ayles H, Floyd S, Mulubwa C, Hensen B, Schaap A, Phiri B, et al. Increasing knowledge of HIV status among men: a clusterrandomised trial of community-based distribution of oral HIV self-test kits nested in four HPTN 071 communities in Zambia. In: 9th IAS conference on HIV science, 23-26 July 2017, Paris, France; 2017.

9. Gichangi A, Wambua J, Gohole A, Mutwiwa S, Njogu R, Bazant E. Provision of oral HIV self-test kits triples uptake of HIV testing among male partners of antenatal care clients: results of a randomized trial in Kenya. In: 21 st International AIDS conference, 18-22 July 2016, Durban, South Africa; 2016.

10. Johnson CC, Kennedy C, Fonner V, Siegfried N, Figueroa C, Dalal S, et al. Examining the effects of HIV self-testing compared to standard HIV testing services: a systematic review and meta-analysis. J Int AIDS Soc. 2017. https://doi.org/10.7448/ IAS.20.1.21594.

11. WHO. Consolidated guidelines on HIV testing services; 5Cs: consent, confidentiality, counseling, correct results and connection. Geneva: WHO; 2015. http://apps.who.int/iris/bitst ream/10665/179870/1/9789241508926_eng.pdf.

12. Wanyenze RK, Musinguzi G, Kiguli J, Nuwaha F, Mujisha G, Musinguzi J, et al. "When they know that you are a sex worker, you will be the last person to be treated": perceptions and experiences of female sex workers in accessing HIV services in Uganda. BMC Int Health Hum Rights. 2017;17(1):11.

13. Chanda M, Perez-Brumer A, Ortblad K, Mwale M, Chongo S, Kamungoma N, et al. Barriers and facilitators to HIV testing among Zambia female sex workers in three transit hubs. AIDS Patient Care STDs. 2017:31(7):290-6. 
14. Lancaster KE, Cernigliaro D, Zulliger R, Fleming PF. HIV care and treatment experiences among female sex workers living with HIV in sub-Saharan Africa: a systematic review. Afr J AIDS Res. 2016;15(4):377-86.

15. Lafort Y, Lessitala F, Candrinho B, Greener L, Greener R, Beksinska M, et al. Barriers to HIV and sexual and reproductive health care for female sex workers in Tete, Mozambique: results from a cross-sectional survey and focus group discussions. BMC Public Health. 2016;16:608.

16. UNAIDS. The gap report. Geneva: UNAIDS; 2014. http://www. unaids.org/sites/default/files/media_asset/UNAIDS_Gap_repor t_en.pdf.

17. Balán IC, Carballo-Diéguez A, Frasca T, Dolezal C, Ibitoye M. The impact of rapid HIV home test use with sexual partners on subsequent sexual behavior among men who have sex with men. AIDS Behav. 2014;18(2):254-62.

18. Frasca T, Balan I, Ibitoye M, Valladares J, Dolezal C, CarballoDiéguez A. Attitude and behavior changes among gay and bisexual men after use of rapid home HIV tests to screen sexual partners. AIDS Behav. 2014;18(5):950-7.

19. Oldenburg C, Chanda M, Ortblad K, Mwale M, Chongo S, Kamungoma N, et al. Effect of HIV self-testing on the number of partners among female sex workers in Zambia: a randomized controlled trial. AIDS. 2017;32(5):645-52.

20. Blanchard AK, Mohan HL, Shahmanesh M, Prakash R, Isac S, Ramesh BM, et al. Community mobilization, empowerment and HIV prevention among female sex workers in South India. BMC Public Health. 2013;13:234.

21. Beattie TSH, Mohan HL, Bhattacharjee P, Chandrashekar S, Isac $\mathrm{S}$, Wheeler T, et al. Community mobilization and empowerment of female sex workers in Karnataka State, South India: associations with HIV and sexually transmitted infection risk. Am J Public Health. 2014;104(8):1516-25.

22. UNAIDS. Ending AIDS: progress towards the 90-90-90 targets. Geneva: UNAIDS; 2017 (cited 1 Aug 2017). http://www. unaids.org/sites/default/files/media_asset/Global_AIDS_updat e_2017_en.pdf.

23. HIVST.org. Policy and regulations for HIVST. HIVST.org (cited 8 Sep 2015). http://www.hivst.org/policy-regulations-for-hivst-1/.

24. WHO. Consolidated guidelines on HIV prevention, diagnosis, treatment and care for key populations. Geneva: WHO; 2016 (cited 12 June 2018). http://apps.who.int/iris/bitstream/10665 /246200/1/9789241511124-eng.pdf.

25. ClinicalTrials.gov. Impact of HIV self-testing among female sex workers in Kampala, Uganda (HSPOT). ClinicalTrials.gov; 2016. https://clinicaltrials.gov/ct2/show/NCT02846402.

26. Closson K, Dietrich JJ, Lachowsky NJ, Nkala B, Palmer A, Cui $\mathrm{Z}$, et al. Gender, sexual self-efficacy and consistent condom use among adolescents living in the HIV hyper-endemic setting of Soweto, South Africa. AIDS Behav. 2017;22(2):671-80.

27. Hong Y, Li X, Fang X, Zhao R. Depressive symptoms and condom use with clients among female sex workers in China. Sex Health. 2007;4(2):99-104.

28. Bachanas P, Medley A, Pals S, Kidder D, Antelman G, Benech I, et al. Disclosure, knowledge of partner status, and condom use among HIV-positive patients attending clinical care in Tanzania, Kenya, and Namibia. AIDS Patient Care STDs. 2013;27(7):425-35.

29. Simbayi LC, Kalichman SC, Strebel A, Cloete A, Henda N, Mqeketo A. Disclosure of HIV status to sex partners and sexual risk behaviours among HIV-positive men and women, Cape Town, South Africa. Sex Transm Infect. 2007;83(1):29-34.

30. Delavande A, Kohler H-P. The impact of HIV testing on subjective expectations and risky behavior in Malawi. Demography. 2012;49(3):1011-36.
31. Weinhardt LS, Carey MP, Johnson BT, Bickham NL. Effects of HIV counseling and testing on sexual risk behavior: a metaanalytic review of published research, 1985-1997. Am J Public Health. 1999;89(9):1397-405.

32. Marks G, Crepaz N, Janssen RS. Estimating sexual transmission of HIV from persons aware and unaware that they are infected with the virus in the USA. AIDS. 2006;20(10):1447-50.

33. Gong E. HIV testing and risky sexual behaviour. Econ J. 2015;125(582):32-60.

34. Haile B. Promoting HIV testing and safe sexual behavior: evidence from a field experiment in Ethiopia. Department of Economics, Columbia University; 2011. https://www.csae.ox.ac.uk/ conferences/2011-EdiA/papers/390-Haile.pdf.

35. Kroenke K, Spitzer RL, Williams JBW. The PHQ-9. J Gen Intern Med. 2001;16(9):606-13.

36. Manea L, Gilbody S, McMillan D. Optimal cut-off score for diagnosing depression with the Patient Health Questionnaire (PHQ-9): a meta-analysis. Can Med Assoc J. 2012;184(3):E191-6.

37. Montori VM, Guyatt GH. Intention-to-treat principle. Can Med Assoc J. 2001;165(10):1339-41.

38. Gupta SK. Intention-to-treat concept: a review. Perspect Clin Res. 2011;2(3):109-12.

39. Ranganathan P, Pramesh CS, Aggarwal R. Common pitfalls in statistical analysis: intention-to-treat versus per-protocol analysis. Perspect Clin Res. 2016;7(3):144-6.

40. Zou G. A modified Poisson regression approach to prospective studies with binary data. Am J Epidemiol. 2004;159(7):702-6.

41. Stevens DR, Vrana CJ, Dlin RE, Korte JE. A global review of HIV self-testing: themes and implications. AIDS Behav. 2018;22(2):497-512.

42. Wright AA, Katz IT. Home testing for HIV. N Engl J Med. 2006;354(5):437-40.

43. Walensky RP, Paltiel AD. Rapid HIV testing at home: does it solve a problem or create one? Ann Intern Med. 2006;145(6):459-62.

44. Horvath KJ, Oakes JM, Rosser BRS. Sexual negotiation and HIV serodisclosure among men who have sex with men with their online and offline partners. J Urban Health Bull N Y Acad Med. 2008;85(5):744-58.

45. Aghaizu A, Wayal S, Nardone A, Parsons V, Copas A, Mercey D, et al. Sexual behaviours, HIV testing, and the proportion of men at risk of transmitting and acquiring HIV in London, UK, 2000-13: a serial cross-sectional study. Lancet HIV. 2016;3(9):e431-40.

46. Campbell C. Selling sex in the time of AIDS: the psycho-social context of condom use by sex workers on a Southern African mine. Soc Sci Med 1982. 2000;50(4):479-94.

47. Karim QA, Karim SS, Soldan K, Zondi M. Reducing the risk of HIV infection among South African sex workers: socioeconomic and gender barriers. Am J Public Health. 1995;85(11):1521-5.

48. Baral S, Beyrer C, Muessig K, Poteat T, Wirtz AL, Decker MR, et al. Burden of HIV among female sex workers in low-income and middle-income countries: a systematic review and meta-analysis. Lancet Infect Dis. 2012;12(7):538-49.

49. Shannon K, Strathdee SA, Goldenberg SM, Duff P, Mwangi P, Rusakova M, et al. Global epidemiology of HIV among female sex workers: influence of structural determinants. Lancet. 2015;385(9962):55-71.

50. CDC. Crane survey: select results from recent surveys, Kampala 2012/3. Kampala (cited 28 March 2017). http://documentslide. com/documents/crane-survey-select-results-from-recent-surve ys-kampala-20123-men-who-have.html.

51. Ortblad K, Kibuuka Musoke D, Ngabirano T, Nakitende A, Haberer JE, McConnell M, et al. Female sex workers often incorrectly interpret HIV self-test results in Uganda. JAIDS. 2018;79(1):e42-5. 
52. Corno L, de Paula A. Risky sexual behaviors: biological markers and self-reported data. CEPR Discuss Paper No. DP10271. http:// www.ucl.ac.uk/ uctpand/cornodepaula_201707.pdf.

53. Gallo MF, Steiner MJ, Hobbs MM, Warner L, Jamieson DJ, Macaluso M. Biological markers of sexual activity: tools for improving measurement in HIV/sexually transmitted infection prevention research. Sex Transm Dis. 2013. https://doi. org/10.1097/OLQ.0b013e31828b2f77.

Publisher's Note Springer Nature remains neutral with regard to jurisdictional claims in published maps and institutional affiliations. 